DOI: http://dx.doi.org/10.17793/rdd.v4i7.810

\title{
1. BUROCRACIA, PODER E FINITUDE: uma análise com a lembrança de Ivan Ilitch.
}

\section{BUROCRACY, POWER AND FINITENESS: an analyses remembering Ivan Ilitch.}

\section{Dartagnan Ferrer dos Santos ${ }^{1}$ Fábio Bortolazzo Pinto ${ }^{2}$}

\begin{abstract}
Resumo: Procura-se neste estudo estabelecer algumas aproximações entre a novela A morte de Ivan Ilitch de Leon Tolstoi e a teoria do direito, usandose também conceitos de outras ciências humanas. Em primeiro lugar, será feita uma análise de importância e contextualização da obra literária. Em seguida, partindo de uma crítica ao exercício do cargo burocrático e seguindo lições de Max Weber, José Martins Catharino e outros, busca-se estabelecer um paralelo entre os problemas advindos da posição de destaque inerente a cargos judiciários de maior prestígio e altos empregados do setor privado. Por fim, às regalias do poder será contraposta uma questão mais primordial, a da finitude da vida.
\end{abstract}

Palavras-chave: Burocracia, poder, poder judiciário, altos empregados.

\begin{abstract}
This study intends to establish some links between the novel "The Death of Ivan Ilitch" by Leon Tolstoi and jurisprudence, also using concepts from other human sciences. At first, there will be an analysis of importance and contextualization of the literary work. Thereafter, it starts from a criticism of the bureaucratic position and following lessons from Max Weber, José Martins Catharino and others, is expected to draw a parallel between the problems created by prominent position inherent in judicial positions most prestigious and high employee the private sector. Finally, the perks of power of will be counterpoised to the most crucial issue of the finiteness of life.
\end{abstract}

Keywords: Bureaucracy, power, judiciary, high employees.

\footnotetext{
${ }^{1}$ Mestre em Direito. Professor do Curso de Direito da Faculdade Inedi, Cesuca. Advogado. E-mail: dartagnansantos@cesuca.edu.br.

${ }^{2}$ Mestre em Letras pela Universidade Federal do Rio Grande do Sul (2006). Licenciatura Em Letras Português e Literaturas de Língua Portuguesa pela Universidade Federal do Rio Grande do Sul (2003). Email: fabiobpinto74@gmail.com.
} 


\section{INTRODUÇÃO}

Em sua novela $A$ morte de Ivan Ilitch, Leon Tolstoi apresenta uma miríade de questões universais e eternas que a tornam fonte para diversos enfoques e exames. Sendo assim, é difícil escolher apenas um aspecto da obra a ser abordado, e, ainda mais difícil dizer algo além do que lá está dito ou "claramente implícito".

Não obstante essas notórias dificuldades, procura-se aqui efetuar uma ligação (mesmo que sutil e/ou tangencial) da obra com o direito e com sua ciência. Para tal, observou-se que, entre as questões principais, 'de vida ou morte', de que trata a novela, uma das tantas discussões acessórias possíveis é a crítica ao exercício do cargo burocrático em que está inserido o ofício de considerável relevância da personagem principal. A vaidade, o orgulho pessoal e a bajulação que advêm do exercício de cargos jurídicos e/ou de gestão são realidades ainda hoje observáveis no dia-a-dia de instituições públicas e privadas. Esses fatores ligados à prática profissional em certos cenários são aqui analisados, enfocando principalmente os problemas e as contradições que deles emergem. Desse modo, se espera estabelecer um paralelo entre a função estatal do juiz Ivan Ilitch e a posição de destaque dos cargos públicos de maior prestígio, bem como a dos 'altos empregados' do setor privado. Por todo o estudo são apresentadas considerações que se nos apresentam como mais relevantes a respeito do assunto, todas nascidas da análise da obra literária e escolhidas por ensejarem um pensar jurídico a respeito do uso do poder nas altas posições estatais e empresariais.

A análise é desenvolvida através de pesquisa bibliográfica, seguindo-se basicamente os seguintes passos: resenha da obra sob a ótica da teoria literária; apresentação de passagens da obra que revelam os traços de caráter e certas fraquezas de Ivan Ilitch; exame de conceitos e crítica à organização formal/burocrática conforme lições de Max Weber; análise do comportamento e da situação dos 'altos empregados' seguindose as lições clássicas de José Martins Catharino. O objetivo primordial e final deste trabalho é estabelecer uma reflexão que aproximar os campos da literatura e da ciência do direito, mantendo no horizonte de análise aquela que é a grande questão temática da obra: a finitude da vida. 


\section{CONSIDERAÇÕES INICIAIS SOBRE UMA NOVELA VISIONÁRIA}

Publicada pela primeira vez em 1886, A Morte de Ivan Ilitch é um corpo estranho na literatura típica do século XIX, a qual foi marcada pela análise objetiva e racional dos fatos sociais. Ainda que a novela de Tolstoi apresente um narrador em terceira pessoa (uma voz objetiva sem envolvimento direto com aquilo que narra), tal narrativa está a serviço de uma crítica profunda à objetividade e ao culto da razão. Trata-se, inclusive, de uma autocrítica. De acordo com Paulo Rónai, "depois de uma juventude dedicada à vida em sociedade, aos jogos e ao álcool, Tolstói percebe a futilidade deste modo de vida e passa a preocupar-se com o sentido da existência e dedicar a este tema sua atividade literária" (RÓNAI, 2009). Talvez essa vivência, essa consciência que leva Tolstoi a apontar para o pragmatismo vazio de sua própria classe seja uma das razões para a percepção de um problema maior, vivenciado 'por dentro': a desconstrução de um mundo que faz sentido, cheio de verdades absolutas e certezas inapeláveis.

\footnotetext{
Quando uma época se aproxima de sua crise, são os artistas que, graças à sua hipersensibilidade, anunciam os tempos vindouros, os tempos que, como correntes secretas e subterrâneas, já fluem sob a época, prontos para converter-se em poderosas torrentes visíveis que arrastarão os velhos conceitos como animais mortos ou troncos caducos. (SÁBATO, 1993:105)
}

Apresentar de maneira tão cabal as "correntes subterrâneas", que desembocariam nas grandes questões da modernidade é, muito provavelmente, o que faz com que a novela cronologicamente pré-moderna de Tolstoi continue dizendo tanto ao leitor contemporâneo.

\section{1 "De outro estofo"?}

O narrador de A Morte de Ivan Ilitch inicia o relato pela notícia da morte do personagem principal, mais especificamente pela recepção da notícia entre os colegas de trabalho de Ilitch. Em seguida, acompanhamos um desses colegas, Piotr Ivanovich, que frequentou junto com o protagonista a Escola de Direito e com quem "considerava-se com certas obrigações". A onisciência do narrador nos permite saber o que passa pela cabeça de Ivanovich quando este cumpre a formalidade de comparecer ao velório e conversar com a 
viúva, interessada em saber quanto lhe pode render, além da pensão regulamentar provida pelo governo, a morte do marido. Interesse dissimulado por lágrimas e 'sincero' sofrimento. Pouco à vontade, Ivanovich nutre sentimentos ambíguos em tal situação. Por um lado, o alívio de não ser ele o defunto e um moderado pesar pela morte do amigo; por outro, a vontade de afastar-se daquela atmosfera pesada e não saber quanto tempo é adequado permanecer.

O ponto que nos parece interessante destacar neste primeiro capítulo são os dois momentos em que Ivanovich encontra outro colega de ofício, Schwartz. Antes de entrar na casa de Ilitch, o primeiro encontro: "Schwartz, colega de Piotr Ivânovich, estava vindo de cima e, tendo visto de um degrau superior aquele que entrava, parou e piscou-lhe um olho, como que dizendo: 'O que Ivan Ilitch fez foi uma tolice; você e eu somos de outro estofo!'” (TOLSTOI, 2009:9). Até esse encontro, Ivanovich não sabe bem o que significa para ele a morte de Ilitch. A postura do colega não o ajuda a encontrar tal significado, mas proporciona um 'índice de conveniência', ou seja, indica não como ou o que Ivanovich deve sentir, mas o que é mais adequado aparentar. Depois de visitar a câmara ardente, Piotr Ivanovich volta a encontrar Schwartz, cujo aspecto dizia:

o incidente das exéquias de Ivan Ilitch não pode de modo algum servir de pretexto suficiente para se considerar alterada a ordem da sessão, isto é, nada poderá impedi-lo de fazer estalar, naquela mesma noite, um baralho de cartas, ao desembrulhá-lo, enquanto um criado colocará quatro velas novas; e em geral, não havia motivo para se supor que aquele incidente pudesse impedi-los de passar agradavelmente também aquela noite. (TOLSTOI, p.11-12)

$\mathrm{O}$ "fazer estalar, naquela mesma noite, um baralho de cartas" refere-se à partida de whist a que Ivanovich pretende comparecer na noite do velório. Divertimento noturno que era, aliás, um dos hábitos do falecido Ilitch. Esse segundo encontro com Scharwtz reforça para Ivanovich o modo como deve se comportar com relação à morte do colega. Já não se trata de sentir, mas de agir de acordo com o que os outros esperam. Ou seja: a ambiguidade dos sentimentos dá lugar à sugestão de conduta social esperada. No fim das contas, a atitude verdadeiramente inadequada é a de Ilitch: morrer.

\section{ESFERAS DE VALOR E "AUTONOMIZAÇÃO”}


Interpretando Max Weber, diz Jürgen Habermas que a modernidade pode ser definida como a passagem de uma concepção de mundo fortemente ligada ao dogmatismo religioso e à percepção metafísica da existência para uma organização social estruturada a partir de dois processos: o de "racionalização" ocorrido nos subsistemas econômico e político (neste incluso o direito e suas instituições, tratando-se de uma análise sociológica), e o de "autonomização", que se distribui em três "esferas de valor": a ciência, a moralidade e a arte (ARANTES:1992, p. 109-110). ${ }^{3}$ A palavra "valor", associada à ciência - ao primado da razão e do conhecimento -, à moralidade - em que opera a justiça, a normatização do comportamento do indivíduo em sociedade -, e à arte - campo da expressão do belo, da 'verdade' e da autenticidade -, refere-se, entre outras coisas, à busca do sujeito social por respeito e destaque junto a uma determinada coletividade. O valor do indivíduo na modernidade pode ser, então, medido por seu grau de instrução, pela adequação de seu comportamento a determinados padrões éticos e à sua sensibilidade estética 'cultivada'. Não é senão o desejo ou mesmo a artificiosa 'necessidade' de alcançar uma posição de status a razão de viver do alto funcionário Ivan Ilitch. Até perceber que a vida, no fim das contas, exige um pouco mais que isso.

De fato, do segundo ao quarto capítulo, o narrador de $A$ Morte de Ivan Ilitch nos apresenta a trajetória do personagem principal, seus anseios, seus esforços, suas conquistas. É onde se evidencia a subordinação do personagem aos preceitos determinados nas três esferas de valor que organizam o processo social de autonomização descrito por Weber. Ivan Ilitch acerca-se delas de maneira absolutamente convencional e moderada. O pragmatismo o leva a adquirir o conhecimento necessário para ser um competente, correto e objetivo jurista.

No desempenho da função de juiz, Ivan Ilitch era igualmente comme il faut $^{4}$, decente, capaz de separar as obrigações funcionais e a vida particular, uma pessoa que inspirava consideração geral, como o fizera igualmente quando funcionário para encargos especiais. (...) Quanto ao serviço propriamente dito, isto é, aos processos de instrução, Ivan Ilitch assimilou muito depressa os meios de afastar de si todas as circunstâncias estranhas, bem como os de enquadrar mesmo os casos mais complicados numa forma graças à qual se apresentassem no papel apenas externamente, excluído de todo o ponto de vista pessoal de Ivan Ilitch e, sobretudo, se cumprissem todas as formalidades exigidas. (TOLSTOI, p. 21-22)

\footnotetext{
${ }^{3}$ O ponto de partida para a reflexão de Habermas é a obra Ciência e Política: duas vocações (1919), de Max Weber.

${ }^{4}$ Em francês: como é preciso.
} 
Diga-se ainda que, na esfera da ciência (do conhecimento, portanto), Ilitch comporta-se tomando como referência aqueles que estão acima na escala social, sem querer superá-los, mas nivelar-se, $\mathrm{O}$ que também acontece no convívio social e na esfera moral. É possível ainda observar que, desde estudante, Ivan Ilitch se abstém de problematizar atitudes de seus modelos pessoais, o que faz crer que muito menos seria ele capaz de criticar a metodologia de seu ensino ou mesmo sua aplicabilidade em momento futuro; para ele, resta cegar-se para o mito do racionalismo jurídico e ser "servil a um normativismo grosseiro que para mais nada serve, senão para a produção de dóceis instrumentos do sistema” (SILVA, 2006:49). A passagem a seguir é reveladora:

\begin{abstract}
Não era um adulador quer quando menino, quer já homem feito, mas, desde a idade mais tenra, era atraído, como o inseto pela luz, pelas pessoas altamente colocadas na sociedade, assimilava suas maneiras, a sua visão da vida, e estabelecia relações amistosas com elas. Passou por todos os arrebatamentos da infância e juventude, sem que estes the deixassem grandes vestígios; entregou-se tanto à sensualidade como à vaidade e, finalmente, nos últimos anos do curso, ao liberalismo, mas tudo dentro de determinados limites, que lhe eram indicados com precisão pelo seu sentimento. (...) Cometeu na Faculdade algumas ações que, antes, pareciam-lhe grande ignomínia e que suscitaram nele asco por si mesmo, no momento em que as cometia; mas, percebendo ulteriormente que essas ações eram cometidas também pelas pessoas altamente colocadas e não eram consideradas por elas como ações más, não é que ele as tivesse considerado boas, mas esqueceu-as de todo e não se entristecia um pouco sequer ao lembrá-las. (TOLSTOI, p. 18-19)
\end{abstract}

No que tange à esfera da arte, Ivan Ilitch é tão convencional e superficial quanto nas duas outras. Aprecia a música que todos dançam; ${ }^{5}$ quando lê algo fora daquilo que o ofício exige, opta pelo romance que todos estão comentando. O momento, porém, em que o narrador explicita o interesse e as noções estéticas de Ilitch, é aquele em que, assumido um cargo que lhe permite certo conforto financeiro, o protagonista dedica-se ao cenário doméstico: à decoração da casa.

Ivan Ilitch supervisionou pessoalmente as reformas, escolheu o papel de parede, comprou outros móveis (na maioria antiguidades consideradas por ele comme il faut), escolheu o material para forração e cortinas e tudo foi tomando forma até tornar-se aquilo a que ele havia se proposto. Mesmo quando as coisas ainda estavam na metade, quase sempre ultrapassavam

\footnotetext{
${ }^{5}$ Com o perdão do trocadilho: como faz em relação às outras esferas de valor, Ivan Ilitch 'dança conforme a música'.
} 
Revista Diálogos do Direito

http://ojs.cesuca.edu.br/index.php/dialogosdodireito/index

ISSN 2316-2112

suas expectativas. Pensava no aspecto refinado e elegante, sem um toque de vulgaridade, que tudo teria quando estivesse pronto. De noite, ao adormecer, punha-se a imaginar como ficaria a sala de estar depois de pronta, e examinando a sala de visitas já dava para ver a lareira, o biombo, o étagère e as cadeiras espalhadas aqui e ali, os pratos nas paredes, os enfeites de bronze (...). Deliciava-se sobretudo em pensar na impressão que causaria em sua esposa e sua filha, elas que tinham tanto bom gosto nesses assuntos. (...) Tudo isso absorvera-o tanto que, embora gostasse muito de seu trabalho, este interessava-o menos do que esperava. Algumas vezes até mesmo distraía-se durante as sessões, ponderando se o bandô da cortina deveria ser reto ou arredondado. (TOLSTOI, p. 30-31)

O que satisfaz sobremaneira a dedicação com que Ilitch decora a própria casa? A apreciação da mulher e da filha, ou seja, mostrar a elas que tem 'bom gosto'. O julgamento externo é sempre o que mobiliza os esforços do juiz de instrução Ivan Ilitch. É, aliás, seu apreço pelo que considera 'belo' a única coisa capaz de desviar sua atenção do trabalho, seu refúgio da turbulenta relação com a mulher, cujo temperamento 'desorganiza' aquilo que ele considera ideal na vida em família ${ }^{6}$. É com grande satisfação que Ilitch convida amigos - geralmente colegas de trabalho - e pessoas influentes para conhecerem sua casa, promovendo pequenos saraus e encontros 'elegantes'. O que pensa, porém, ser uma atmosfera distinta, capaz de impressionar os convidados, não ultrapassa a mediania que caracteriza, de modo geral, tudo que ele faz.

Na realidade, o efeito não passava do que normalmente é visto nas casas de pessoas que não são exatamente ricas, mas que querem parecer ricas e o máximo que conseguem é parecer-se com todas as outras pessoas de sua classe (...), tudo aquilo que as pessoas de uma determinada classe social possuem para parecerem outras pessoas. E no caso dele o efeito era tão exato que não causava impressão alguma. (TOLSTOI, p. 31)

É nesse cenário idílico que, quando Ilitch pensa que tudo está 'pronto' e ‘em seu lugar' que algo, sem qualquer aviso, se intromete na vida exemplar do alto funcionário Ivan Ilitch: a doença e a perspectiva da morte. Nada em sua luta por adequação e destaque social o havia preparado para tal 'imprevisto'. Após cair de uma escada (justamente quando está mostrando a um empregado como quer a disposição de algum objeto na parede), o protagonista começa a sentir dores. A princípio, Ilitch não dá importância ao incômodo, que logo se torna mais severo. Do quarto capítulo até o final da narrativa o

\footnotetext{
${ }^{6}$ Não nos aprofundaremos nesse aspecto para não ultrapassar os limites deste artigo ou fugir do escopo da análise proposta.
} 
leitor acompanha a gradual decadência física do personagem; mais que isso, se testemunha a desconstrução de tudo aquilo que a personagem pensava preencher e dar sentido à existência.

\section{BUROCRACIA CONFORME MAX WEBER}

A detalhada organização formal é a regra em todas as instituições e empresas de nosso tempo. Dentro do sistema geral são estabelecidos vários setores para divisão de tarefas a serem exercidas com alta especialização e com normas e sistemáticas bem definidas. Para Max Weber, a "burocracia moderna" é o que melhor representa essa organização, a qual trabalha principalmente através de "competências oficiais fixas, ordenadas, de forma geral, mediante regras [e] pelo princípio da hierarquia de cargos em sequência de instâncias, [...] com fiscalização das inferiores pelas superiores" (WEBER, 1999). O sociólogo afirma também que "o capitalismo racional moderno baseia-se nos meios técnicos de produção e em um determinado sistema jurídico, além de uma administração orientada por regras formais" (JOHNSON, 1997:164).

Cabe mencionar também o conceito weberiano de "prestígio", pelo qual, na sociedade estratificada, o prestigioso funcionário recebe "honrarias" e "deferências" em razão da "pressuposição de superioridade" que acompanha sua posição. Trata-se no caso do "prestígio ocupacional" (JOHNSON, 1997). Evidentemente, quanto mais alta a posição da classe no estrato social, maior é o prestígio - como o é a riqueza e o poder. É possível dizer que, naquele tempo e espaço, Ivan Ilitch ocupava um lugar da "alta administração", o que justificava suas regalias e bajulações, não obstante se observe essa natureza de distorção que se em nossa realidade cotidiana.

Porém, embora a inegável vitória dessa sistemática organizacional (a qual é adotada por quase todas as grandes estruturas e instituições do mundo moderno), é fato que inúmeros problemas advêm daí. Em primeiro lugar, a rigidez da estrutura burocrática costuma minar sua eficiência, pois sua estruturação pesada e direcionada "torna também difícil que se enfrente situações imprevisíveis e radicalmente novas. E estimula também empregados a seguir cegamente as regras, mesmo quando isso pode prejudicar os objetivos da organização" (JOHNSON, 1997:164). Muito lembrado por fazer de rigidez, formalismo, tradição e suposta "neutralidade" suas regras, não é difícil transpor tais críticas para o 
poder judiciário e sua ideologia. A esse respeito, vale transcrever literalmente a lição de Ovídio A. Baptista da Silva:

\begin{abstract}
Este isolamento do magistrado - que busca distância até mesmo dos advogados da causa -, além de fortalecer o acentuado corporativismo da instituição, favorece o espírito burocrático, tão acentuadamente presente em nosso Poder Judiciário, na medida em que o juiz, por força desse isolamento social, conserva-se um "elemento da organização", de quem se torna dependente, através de um sufocante sistema de controle administrativo e recursal. A perda da legitimidade social de nossos juízes é uma das tantas consequências do modo como o Poder Judiciário inseriuse no poder burocrático, próprio do Estado contemporâneo. (SILVA, p.45)
\end{abstract}

No tópico a seguir se pretende ultrapassar as fronteiras do poder público para se analisar os empregados que estão no topo da burocracia empresarial e que, por isso, exercem poder assemelhado àquele de Ivan Ilitch em ambiente tipicamente burocrático.

\title{
3.1 Altos empregados:
}

No âmbito da burocracia empresarial, entende-se por "altos empregados" aqueles que ocupam cargos de elevada importância para a empresa, encontrando-se não raramente em situação análoga aos seus empregadores, na confortável condição de gerentes, diretores, etc. Detentores de função de especial confiança, gravitam eles em uma zona gris da prestação laboral, não raro entre a condição de "subordinado" e "subordinante". 7 É o caso daqueles que fazem parte da direção empresarial. Desse modo, esses altos empregados, do topo da hierarquia da empresa, exercem grande parte do poder de direção do trabalho. Sobre eles, diz José Martins Catharino que sua subordinação à empresa decresce "na proporção inversa do grau hierárquico" pois, quanto mais o trabalhador ascende na escala empresarial, menos subordinado ele está (CATHARINO, 1982:210). Nessa condição, a subordinação ao empregador se ameniza na mesma medida em que a liberdade, o poder decisório, as boas condições de trabalho e a remuneração aumentam.

\footnotetext{
7 A "subordinação" é o mais importante dos elementos da relação de emprego, refletindo o "poder diretivo" da empresa sobre o empregado, que está sob "dependência" daquela. A consolidação das Leis do Trabalho define os sujeitos do contrato laboral tendo em vista esses pressupostos: "Art. $2^{\circ}$ - Considera-se empregador a empresa, individual ou coletiva, que, assumindo os riscos da atividade econômica, admite, assalaria e dirige a prestação pessoal de serviço. Art. $3^{\circ}$ - Considera-se empregado toda pessoa física que prestar serviços de natureza não eventual a empregador, sob a dependência deste e mediante salário. Cf. BRASIL. Consolidação das Leis do Trabalho. Disponível em < http://www.planalto.gov.br/ccivil_03/decreto-lei/del5452.htm > Acessado em 10 de novembro de 2014.
} 
Vale transcrever parte dessa clássica lição de Catharino inclusa em "O contrato de emprego":

O empregador é, por excelência, o organizador e quem dirige o trabalho alheio dentro da empresa. [Porém,] além da dissociação entre o dirigir e o executar, que exige subordinação, mesmo o dirigir, principalmente nas empresas de médio ou grande porte, está sujeito a uma divisão de trabalho. Esta é que determina a existência dos colaboradores do empregador, empregados ou não. Quando a intensidade de colaboração suplanta inteiramente a subordinação, no plano jurídico, desaparece a relação de emprego. Quando, porém, a subordinação apenas é afetada pela colaboração jurídica, que a reduz com o consequente acréscimo de autonomia do trabalho, dá-se uma atenuação da primeira, embora não ao ponto extremo de desqualificar a relação de emprego. Esta é a situação em que se acham os altos-empregados, co-participantes das tarefas empresárias a cargo do empregador, quase empregadores-colaterais, os quais, por força de suas funções, são menos empregados, e dos simplesempregados, se distinguem até psicologicamente. Irresistivelmente, por naturais inspirações, adquirem certa mentalidade patronal e, pelos salários elevados que percebem, merecem menor proteção, sendo que sociologicamente, vão incorporar-se à classe média. Em outro sentido, aburguesam-se, tornam-se conservadores e, muitas vezes, se mostram "antiproletários". Acomodam-se porque estão satisfeitos com o de que já desfrutam. A ordem jurídica não pode desconhecer tal situação, sob pena de acolher a injustiça e fomentar a desigualdade. Justo e lógico, portanto, que não se dê aos altos-empregados o mesmo tratamento dado aos empregados comuns, obedecendo-se, aliás, ao princípio da igualdade perante a lei. (CATHARINO, p.457)

Em nosso sistema jurídico existem quatro categorias desses altos empregados: 1) Os ocupantes de cargos de gestão ou confiança - "gerentes" de departamento ou filial que têm autonomia e poder decisórios suficientes para que sejam reputados "de confiança"; 2) Os detentores de cargos ou funções de confiança no segmento bancário; 3) Os colaboradores que estão no mais alto ponto da estrutura de poder na empresa, na condição de diretores típicos, os quais realmente decidem os rumos do empreendimento e/ou do setor que regem. 4) Por fim, discute-se a possibilidade de o sócio da pessoa jurídica ser ao mesmo tempo empregado da entidade (DELGADO, 2007).

Como se denota da lição de Catharino, essa categoria de empregados no mínimo integra as "camadas médias altas" da sociedade de classes (quando não a "classe gerencial"8), sobre a qual Gilberto Velho (1997:120) apontou alguns fatos interessantes, como a sua "individualização radical" que eventualmente pode ensejar até "o afastamento

\footnotetext{
${ }^{8}$ "Nas sociedades capitalistas industriais, a classe gerencial é uma camada situada perto do topo da estrutura de classe, imediatamente abaixo da classe alta. Embora compartilhe de muitas características da mesma, a base de sua posição se situa menos na propriedade dos meios de produção do que no controle que sobre eles exerce" (JOHNSON, 1997:36).
} 
da família" quando esta não consegue acompanhar seu prestígio social. Ivan Ilitch afastouse de seu núcleo mais próximo por motivos outros; mas rejeitava fortemente seu irmão “fracassado" e esquecido, com quem era lamentável encontrar. Porém, como se mencionou acima, a morte é a questão recorrente de nosso tempo; não é mais possível fechar os olhos para sua inevitabilidade, a qual vale para o mais humilde operário tanto como para o mais graduado administrador de grupos empresariais. É comum que o nosso cotidiano corrido e burocrático nos afaste dessa realidade (o que, em regra, é mesmo o nosso desejo); não obstante, a hora final chegou para o juiz de instrução Ivan Ilitch e chegará para todos.

\section{O EXERCÍCIO DO PODER POR IVAN ILITCH}

Afirma Gregório Peces-Barba Martínez que o poder "se trata de uma realidade complexa, [o que] deriva tanto da pluralidade de seus componentes, como de sua interrelação com o direito [que] dele é inseparável” (MARTÍNEZ, 2004:231) ${ }^{9}$. De fato, hoje já está consagrada a ideia de Michel Foucault de que o poder emana e se exerce em múltiplas instâncias e setores da sociedade, atuando em múltiplas direções e de inúmeras formas (inclusive de maneira imperceptível). Ainda assim, é possível dizer que, em seu sentido hierárquico mais elementar, "poder [é] a capacidade, faculdade ou possibilidade de realizar algo [...] conferida por uma autoridade institucional" (JAPIASSÚ e MARCONDES, 2006:220). Pode-se inserir nesta concepção mais tradicional o cargo de juiz de instrução que marcou o topo da carreira profissional de Ivan Ilitch.

Lamentavelmente, o personagem exerceu seu ofício mais importante por pouco tempo. Em razão da decadência rápida e inesperada de sua saúde, a vida de Ivan teve seu desfecho aos quarenta e cinco anos, o que não impediu que esse limitado período trouxesse grande orgulho e inúmeras regalias e prerrogativas ao magistrado. Ele pode assim "passar com desenvoltura, em seu uniforme talhado por Charmer, junto aos solicitantes trêmulos que esperavam ser recebidos e aos outros funcionários, que o invejavam"; isso quando Ivan ia garbosamente tomar chá e fumar com o chefe. Em sua condição de juiz de instrução, a personagem "sentia que todos, todos sem exceção, mesmo as pessoas mais importantes e convencidas, estavam em suas mãos”. Ainda que Ivan Ilitch não tivesse abusado de seu

\footnotetext{
${ }^{9} \mathrm{O}$ autor realça essa "mescla" (nesse estrito termo!) entre poder e direito, a qual diz ocorrer no real, sendo que "só em um paradigma teórico [ambos] se pode separar".
} 
poder, "a consciência dessa autoridade e a possibilidade de atenuá-la constituíam para ele o interesse principal” em exercê-la (TOLSTÓI, 2009:21).

Tais passagens da novela retratam a vaidade e a arrogância que o poder advindo do cargo público de prestígio pode gerar. Quando isso ocorre, a mediocridade ou o vazio no exercício da função é mero detalhe; o próprio resultado do trabalho exercido passa a importar muito pouco pois, embriagado pelo cargo, esse detentor espera é bajulação, benesses, convites e resultados financeiros provenientes da função exercida. Desse modo, ocorre um desvio e o cargo passa de mero instrumento para execução de certos objetivos a um fim em si. Nesses termos, o que encantava aquele juiz de instrução não era o serviço público que devia prestar, mas sim os rituais, os procedimentos, a retórica, o jogo de aparências e outros acessórios. O resultado disso tudo (tão importante para aqueles que se dirigiam ao magistrado) era nitidamente irrelevante para Ivan Ilitch. Certamente, esse não seria o melhor caminho a ser seguido.

\section{CONSIDERAÇÕES FINAIS:}

O conhecimento adquirido, que lhe permite desempenhar com eficácia a função de magistrado, o comportamento, as opiniões e posturas que lhe proporcionam respeitabilidade social, a correta apreciação estética daquilo que julga 'expressão artística', nada disso preparara Ilitch para conviver com o inevitável: a solidão dos moribundos.

\footnotetext{
Ultimamente, na solidão em que se encontrava, deitado com o rosto virado para as costas do sofá, solidão no meio de uma cidade superpovoada e rodeado de inúmeros desconhecidos - solidão mais completa do que qualquer outra, seja no fundo do mar ou no centro da Terra - nessa assustadora solidão, Ivan Ilitch vivia somente das lembranças do passado. Um após o outro, os retratos do seu passado iam aparecendo para ele. (TOLSTOI, p. 69)
}

O fato de jamais ter pensado na doença ou na morte como parte da vida (já que escolheu viver 'do lado de fora', ou seja, priorizando o olhar alheio), Ilitch não tem qualquer controle sobre suas reações à doença. Ao passo em que o problema se torna mais grave, maior é sua irritabilidade. Deprime-se, foge ao contato com os que o cercam. A relação com a mulher e com os filhos, que nunca fora muito afetuosa, deteriora-se, torna-se ainda mais seca e distante: "Via que todos que o rodeavam, especialmente sua esposa e 
filha, tão absorvidas por compromissos sociais, não só não tinham um pingo de compreensão, como ainda se irritavam por ele andar tão deprimido. (...) Por mais que tentassem disfarçar, ele via que estava atrapalhando-lhes o caminho". (TOLSTOI, 2009:41-42). Dentro de si, Ilitch encontra a infância, a primeira juventude, o tempo anterior à total adequação social. Tudo mais lhe parece vazio e sem sentido.

Veio-lhe à cabeça a ideia de que aquela sua leve inclinação para lutar contra os valores das classes altas, aqueles impulsos de rebeldia que mal se notavam e que ele havia tão bem aplacado talvez fossem a única coisa verdadeira, e o resto todo, falso. E suas obrigações profissionais e a retidão de sua vida e sua família e sua vida social tudo falso e sem sentido. (TOLSTOI, 72)

A parte final de A Morte de Ivan Ilitch é uma das descrições mais comoventes do processo de decadência física, de luta contra a morte, que se pode encontrar na literatura mundial. E, mais importante para o que nos propomos aqui analisar: antecipa e influencia a maneira como o tema é tratado por escritores que vieram depois de Tolstoi, pois a morte torna-se um tópico quase obrigatório na arte do século $\mathrm{XX}$, especialmente depois da Primeira Guerra Mundial.

Sobre quase toda a grande literatura de hoje pesa o problema da morte, problema que se aguça quando o prazo é conhecido. Desde $O$ Idiota até $O$ Estrangeiro. É que a morte a prazo fixo, a morte sabida e esperada minuto a minuto, propõe peremptoriamente os enigmas que a morte natural deixa como esquecidos: na vida cotidiana, procedemos como se fôssemos eternos; trabalhamos, lutamos pelo porvir, sofremos com insignificâncias, como se tivéssemos de viver eternamente. Quando fazemos sofrer um ser querido, é porque o julgamos eterno. (SÁBATO, 1993:113)

Sem grande exagero, pode-se afirmar que dificilmente se encontrará autor que supere a maestria com que Tolstoi analisou a questão em pauta. Especialmente se atentarmos para o contraste estabelecido entre a vida social e profissional do protagonista e sua agonia ao perceber que nada o diferencia de outros seres humanos. Também de nada serve o (mitológico) racionalismo jurídico que "supunha ser o Direito uma ciência tão exata quanto a matemática" (SILVA, 2006:55). ${ }^{10} \mathrm{O}$ autor parece nos dizer que a ciência, a

\footnotetext{
${ }^{10}$ Ao fazer a crítica ao racionalismo jurídico (e mais ainda ao discurso de que ele nada vale acompanhado de uso e sua defesa diárias), Ovídio A. Baptista da Silva lembra "a conhecida separação entre o dictum e o factum", expondo que todos repetem que esse racionalismo "está definitivamente morto e sepultado. É o
} 
Revista Diálogos do Direito

http://ojs.cesuca.edu.br/index.php/dialogosdodireito/index

moral e a arte só têm real valor quando transcendem a esfera do social e imanente, nos permitindo compreender e significar a vida em todas as suas instâncias. Diante da finitude, poder, ciência, altos cargos, bons salários e o conforto material proporcionados não têm qualquer importância.

\section{REFERÊNCIAS BIBLIOGRÁFICAS:}

BRASIL. Consolidação das Leis do Trabalho. Disponível em < http://www.planalto.gov.br/ccivil_03/decreto-lei/del5452.htm $>$ Acessado em 10 de novembro de 2014.

CATHARINO, José Martins. Compêndio de direito do trabalho. 3. ed. rev. atual. e aum. São Paulo: Saraiva, 1982.

Contrato de emprego: com comentários aos arts. 442/510 da CLT. 2. ed. rev., atual. e aum. Guanabara: Edições Trabalhistas S.A., 1965.

DELGADO, Maurício Godinho. Curso de direito do trabalho. 6. Ed. São Paulo. LTr, 2007.

HABERMAS, Jürgen. O discurso filosófico da modernidade. São Paulo: Martins fontes, 2000.

JAPIASSÚ, Hilton e MARCONDES, Danilo. Dicionário básico de filosofia. 4. ed. atual. Rio de Janeiro. Editora Zahar, 2006.

JOHNSON, Allan. Dicionário de Sociologia: Guia Prático da Linguagem Sociológica. Rio de Janeiro: Jorge Zahar Editor, 1997.

MARTÍNEZ, Gregório Peces-Barba (Com la colaboración de: Rafael de Asís Roig y Maria del Carmen Barranco Avilés). Lecciones de derechos fundamentales. Madrid: Editorial Dykinson, 2004. (Colección Derechos Humanos y Filosofía del Derecho) realizar essa quimera, como encantamo-nos com suas virtudes milagrosas. É o factum.” (Loc. cit.) 
RÓNAI, Paulo. "Sobre Tolstoi e a Morte de Ivan Ilitch" In: A Morte de Ivan Ilitch. São Paulo: Editora 34, 2009, p. 83-92.

SÁBATO, Ernesto. Homens e Engrenagens. Campinas: Papirus, 1993.

SILVA, Ovídio Araújo Baptista da. Processo e ideologia: o paradigma racionalista. 2. ed. Rio de Janeiro. Editora Forense, 2006.

TOLSTÓI, Lev. A morte de Ivan Ilitch. Tradução, posfácio e notas: Boris Schnaiderman. 2. ed. São Paulo. Editora 34. 2009.

VELHO, Gilberto. Individualismo e cultura: notas para uma antropologia da sociedade contemporânea. 2. ed. Ed. Zahar. Rio de Janeiro, 1997.

WEBER, Max. Economia e sociedade: fundamentos da sociologia compreensiva. V. 2. Ed. Universidade de Brasília. São Paulo, 1999.

(Artigo submetido em 15/12/2014 e aceito em 30/12/2014) 